\title{
Suppressive Effects of Rosmarinic Acid on Mesangioproliferative Glomerulonephritis in Rats
}

\author{
Toshiaki Makino ${ }^{\mathrm{a}}$ Takahiko Ono $^{\mathrm{b}}$ Ning Liu $^{\mathrm{b}}$ Tomoko Nakamura \\ Eri Muso ${ }^{c}$ Gisho Honda ${ }^{a}$ \\ aDepartment of Pharmacognosy, Graduate School of Pharmaceutical Sciences, and bDivision of Nephrology, \\ Department of Cardiovascular Medicine, Graduate School of Medicine, Kyoto University, Kyoto; \\ cDivision of Nephrology, Tazuke-Kofukai, Medical Research Institute Kitano Hospital, Osaka, J apan
}

\section{Key Words}

Mesangioproliferative glomerulonephritis - Labiatae herbs · Mesangial cell proliferation · Fibronectin · Fibrin · Rosmarinic acid

\begin{abstract}
Background: Rosmarinic acid is known to be a natural phenolic compound widely distributed in Labiatae herbs such as rosemary, sweet basil, and perilla. In the present study, we evaluated the suppressive effects of rosmarinic acid on mesangioproliferative glomerulonephritis in vivo, which was induced by intravenous injection of rabbit anti-rat thymocyte serum (ATS) to rats. Methods: Rosmarinic acid was orally administered to the rats at a dose of $100 \mathrm{mg} / \mathrm{kg} /$ day from the day of ATS injection (day $0)$ to day 8 when rats were sacrificed. The degree of mesangial cell proliferation and matrix accumulation were evaluated by trichrome staining and by immunostaining for proliferating cell nuclear antigen (PCNA), fibronectin, type IV collagen and fibrin. Superoxide dismutase (SOD)-activity in the homogenate of renal cortex was also evaluated. Results: The number of PCNA-posi-
\end{abstract}

tive cells, staining areas of trichrome, fibronectin, collagen IV and fibrin in the glomerulus were significantly decreased, and SOD-activity of renal cortex homogenate was significantly augmented in rosmarinic acid-treated group. Conclusion: Rosmarinic acid would suppress the proliferation of mesangial cells and glomerular matrix expansion in vivo by its fibrinolytic and anti-oxidative activity.

Copyright $\odot 2002$ S. Karger AG, Basel

\section{Introduction}

Rosmarinic acid (fig. 1) is a widely distributed phenolic compound in various Labiatae herbs such as $O c i$ mum basilicum (sweet basil), Melissa officinalis (lemon balm), Rosmarinus officinalis (rosemary), Mentha spicata (spearmint), and Perilla frutescens (perilla) [1-3]. Rosmarinic acid is reported to exhibit anti-inflammatory effects, including the inhibition of complement $\mathrm{C} 3$ convertase [4], C5 convertase [5], the covalent attachment to activated C3b [6], 5-lipoxygenase [7], hyaruronidase [8], histamine releases from mast cells [9], and to scavenge

\section{KARGER \\ Fax +4161306 1234 \\ E-Mail karger@karger.ch \\ www. karger.com

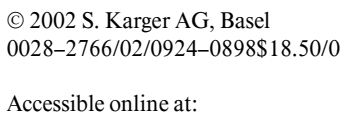

Takahiko Ono, MD

Division of Nephrology, Department of Cardiovascular Medicine

Graduate School of Medicine, Kyoto University

54 Shogoin-Kawaracho, Sakyo-ku, Kyoto 606-8507 (Japan)

Tel. +81 75751 3190, Fax +81 75752 0856, E-Mail ono@kuhp.kyoto-u.ac.jp 
reactive oxygen species $[10,11]$. In the previous in vitro study, we revealed that rosmarinic acid inhibit cytokineinduced murine mesangial cell proliferation [12], suggesting that rosmarinic acid may be useful for preventing the progression of mesangioproliferative glomerulonephritis.

Anti-thymocyte serum (ATS)-induced rat nephritis is known as an experimental model for mesangioproliferative glomerulonephritis, referred to as Thy- 1 nephritis [13]. ATS contains antibodies against Thy-1, originally an antigen of thymocyte and also appearing in rat glomerular mesangial cells. ATS selectively stimulates mesangial cells to proliferate, causing symptoms similar to human mesangioproliferative glomerulonephritis [13]. Thy-1 nephritis is characterized by initial mesangiolysis, platelet and monocyte/macrophage infiltration, and subsequent mesangial cell proliferation and mesangial matrix expansion [14].

In the present study, we evaluated the inhibitory effects of rosmarinic acid on mesangial cell proliferation in vivo, using the experimental model of ATS-induced glomerulonephritis, and found that the oral administration of rosmarinic acid suppressed both the cellular proliferation and the extracellular matrix accumulation in glomeruli.

\section{Materials and Methods}

\section{Preparation of Rosmarinic Acid}

Leaves of Perilla frutescens ( $4.5 \mathrm{~kg}$ fresh weight), which were cultivated in the Experimental Station for Medical Plant Research, Faculty of Pharmaceutical Sciences, Kyoto University and were harvested in August 1997, was extracted with 21 liters of methanol for 1 week at room temperature. The extract was concentrated at reduced pressure to yield $184.2 \mathrm{~g}$ dry weight (extract ratio: $4.1 \%$ ). The extract was partitioned between hexane and $\mathrm{H}_{2} \mathrm{O}$, and then ethyl acetate and $\mathrm{H}_{2} \mathrm{O}$ under $\mathrm{HCl}$-acidified condition ( $\mathrm{pH}$ 3.0) to yield an ethyl acetate layer. This layer was repeatedly subjected to silica gel column chromatography $\left(\mathrm{CHCl}_{3} / \mathrm{MeOH} 19: 1\right)$ to yield $4.8 \mathrm{~g}$ of rosmarinic acid, which is identified by the spectra of ${ }^{1} \mathrm{H}$ or ${ }^{13} \mathrm{C}$-nuclear magnetic resonance and fast atom bombardment-mass spectrometry [15]. For administration, rosmarinic acid was dissolved in water as sodium salt.

\section{Experimental Design}

Mesangioproliferative glomerulonephritis was induced in 6week-old male Wistar rats (Shimizu Laboratory Materials, Kyoto, Japan) by the intravenous injection of rabbit ATS, which was prepared as earlier reported [13] and kindly provided by Nippon Shinyaku Co. (Kyoto, Japan). Twenty-four rats were divided into four experimental groups ( $n=6$, respectively): normal group, injection of normal rabbit serum and treatment with tap water; control group, injection of ATS $(0.2 \mathrm{ml} / \mathrm{kg} \mathrm{BW})$ and treatment with tap water; rosmarinic acid group, injection of ATS and treatment with rosmarinic acid $(100 \mathrm{mg} / \mathrm{kg} /$ day); prednisolone (PSL)-group, injection of ATS

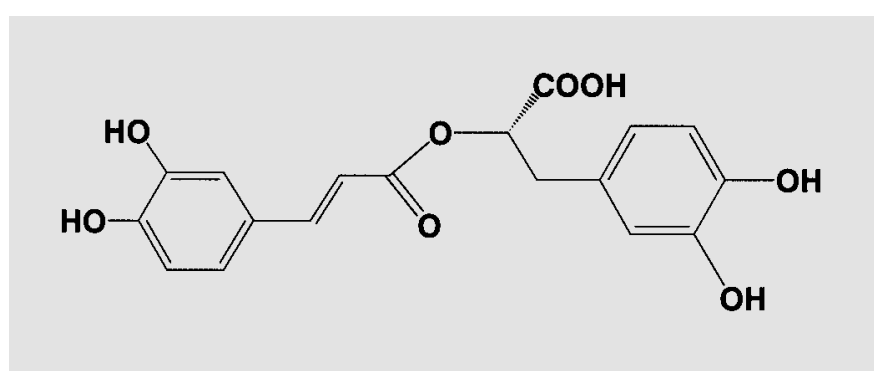

Fig. 1. Structure of rosmarinic acid.

and treatment with PSL ( $2 \mathrm{mg} / \mathrm{kg} /$ day). Rosmarinic acid and PSL were orally administered as drinking water ad libitum from the day of serum injection (day 0) to day 8 , respectively. An amount of drinking water was checked daily, and a mean dosage was controlled by adjusting the concentration of drugs. All rats were sacrificed on day 8 , when sera and kidneys were collected. All rats were handled in accordance with Guiding Principles for the Care and Use of Experimental Animals in Kyoto University.

\section{Measurement of Urinary Albumin}

Urinary albumin levels from 24-hour urine samples collected on day 4 after the serum injection were measured by enzyme-linked immunosolvent assay (ELISA) using a commercial kit (Nephrat, Philadelphia, Pa., USA).

\section{Histological Evaluation of Renal Tissue}

Kidney tissues were fixed in $10 \%$ neutral-buffered formalin $(\mathrm{pH}$ 7.4), embedded in paraffin, and then sections $(4 \mu \mathrm{m})$ were treated with trichrome staining, which was evaluated quantitatively by measuring the blue-staining areas in 20 selected glomerular cross-sections with NIH Image (NIH, Bethesda, Md., USA), and expressed as the staining areas of glomerulus. The sections $(4 \mu \mathrm{m})$ were also stained with a mouse monoclonal antibody against proliferative cell nuclear antigen (PCNA) using a DAKO EPOS anti-PCNA/HRP kit (DAKO Corp., Carpinteria, Calif., USA), and with a rabbit antibody against mouse type IV collagen (Chemicon, Temecula, Calif., USA) and against mouse fibronectin (Biogenesis Ltd., Poole UK) or a goat antibody against rat fibrinogen (ICN, Aurora, Ohio, USA), using ABC Elite peroxidase staining kit (Vector Laboratories Inc., Burlingame, Calif., USA) [16]. The sections were counterstained with hematoxylin. The average number of PCNA positive cells in a glomerular cross section was evaluated by counting the cells in 40 glomeruli in each section. The glomerular deposition of type IV collagen, fibronectin and fibrin were evaluated quantitatively by measuring the positive areas of each staining in 20 selected glomerular cross-sections by NIH Image, and expressed as the staining areas of glomerulus.

Measurement of Super Oxide Dismutase (SOD) Activity in the Kidney Homogenate

Renal cortex was detached with scissor, and homogenated in $5 \mathrm{~m} M$ Tris buffer ( $\mathrm{pH}$ 7.4) on ice. SOD activity in the homogenate was measured by the modified method of Higuchi et al. [17]. $10 \mu \mathrm{l}$ of the homogenate $(15 \mathrm{mg} / \mathrm{ml})$ was mixed with $80 \mu \mathrm{l}$ of $0.25 \mathrm{~m} M$ xanthine, $10 \mu \mathrm{l}$ of $10 \mathrm{~m} M$ hydroxyamine chloride, $20 \mu \mathrm{l}$ of $10 \mathrm{mU} / \mathrm{ml}$ 

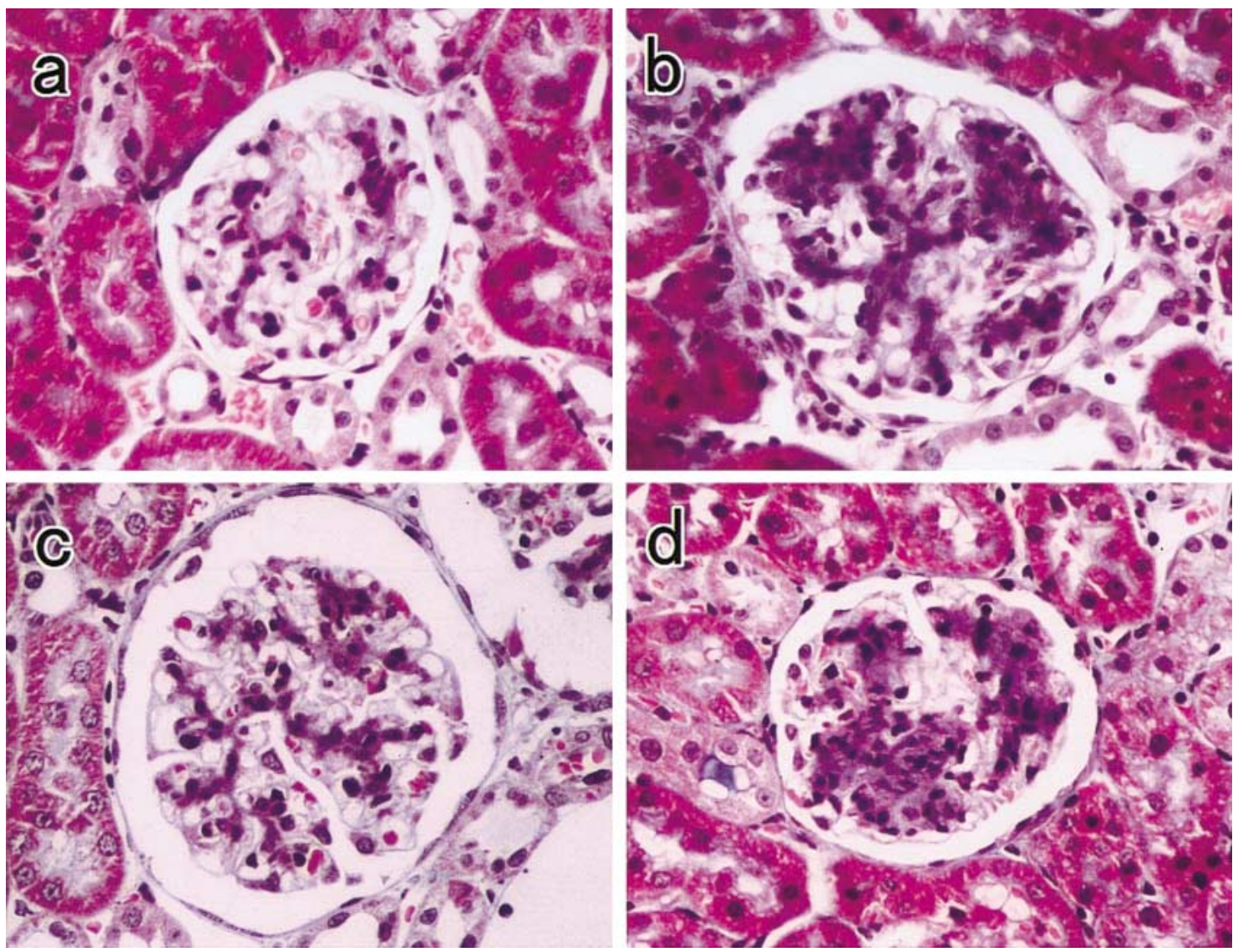

Fig. 2. Trichrome-stained tissue of mesangioproliferative glomerulonephritis induced with ATS. Matrix expansion was markedly induced in the control group (b) compared to the normal group (a), which was suppressed by the treatment of rosmarinic acid (c) and prednisolone (d). Final magnifiation, $\times 250$.

xanthine oxidase (Wako), and then incubated at $37^{\circ} \mathrm{C}$ for $30 \mathrm{~min}$. Generated free radicals in the reaction mixture were detected by adding $150 \mu$ of detecting solution $(30 \mu M \mathrm{~N}$-naphthylethylenediamine/ $3 \mathrm{~m} M$ sulfanilic acid) and measuring an optical density at $540 \mathrm{~nm}$. SOD activity of the kidney homogenate was calibrated by a standard SOD (Wako). The experiment was conducted in duplicate.

\section{Statistical Analysis}

Values are represented as mean \pm SE. The statistical significance was determined by Student's $t$ test except for the evaluation of urinary protein, which was determined by the Mann-Whitney U test for its wide scatter. A difference of $p<0.05$ was considered statistically significant.

Fig. 3. Suppressive effects of rosmarinic acid on trichrome-staining area. The staining areas $\left(\mu \mathrm{m}^{2}\right)$ in the glomeruli of the rats were measured by NIH image. Values are represented as mean \pm SE $(n=6)$. PSL $=$ Prednisolone. ${ }^{* * *} \mathrm{p}<0.001$ vs. control.

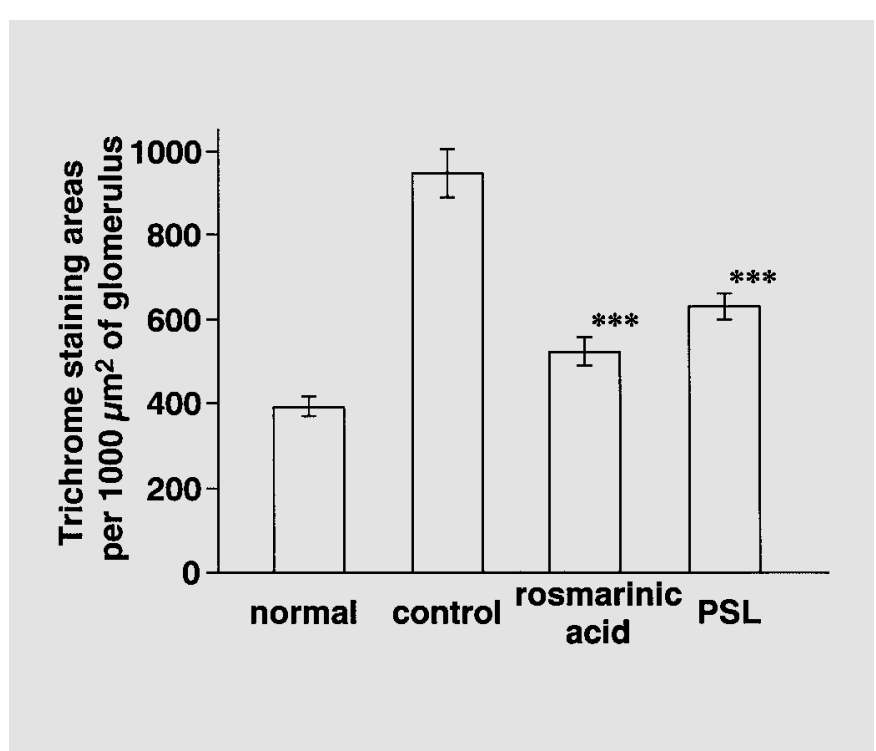

Makino/Ono/Liu/Nakamura/Muso/Honda 
Fig. 4. Photographs of PCNA-stained tissue of mesangioproliferative glomerulonephritis induced with ATS. The glomerulus of control rats with PCNA-positive cells (arrow) (a) and rosmarinic acid-treated rats $(\mathbf{b})$ were shown. Final magnification, $\times 200$.
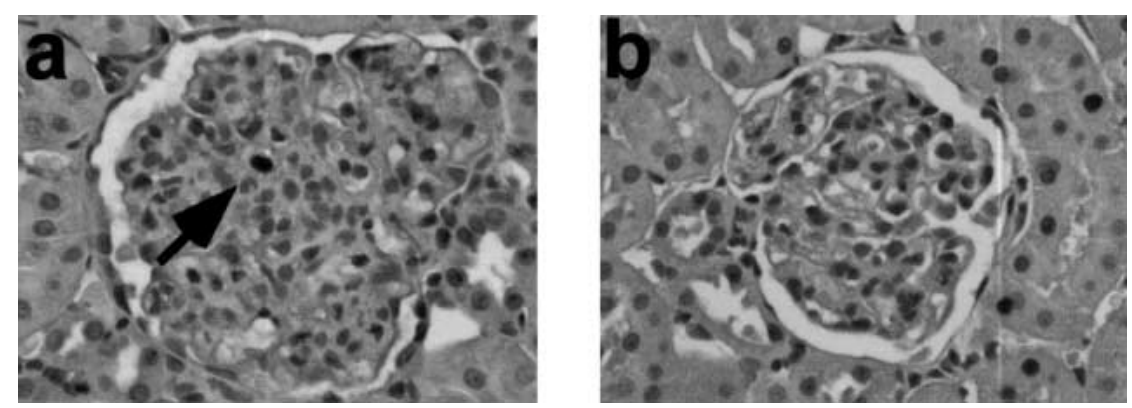

\section{Results}

Rosmarinic acid was orally administered to the rats after the injection of ATS. When the rats were sacrificed 8 days after the injection, no significant differences in the weights of the body, heart, liver, spleen, or kidneys were observed among rats of the normal group, control group, and rosmarinic acid-treated groups. PSL-treated rats significantly reduced their body weight (control, $232.8 \pm$ 6.9; PSL, $207.0 \pm 4.2, \mathrm{p}<0.01 ; \mathrm{g}$ ).

In this animal model, proteinuria is maximum on the day 4 after the injection of ATS [18]. In control rats, the amount of urinary albumin was markedly increased, which was significantly reduced in rosmarinic acidtreated rats (normal, $44 \pm 12$; control, $1,239 \pm 585$; rosmarinic acid, $167 \pm 66, \mathrm{p}<0.05$ vs. control; albumin $\mu \mathrm{g} /$ day).

Histological evaluation using trichrome staining showed that the positive area of trichrome staining in glomeruli was highly augmented in the control group compared to the normal group, which was significantly suppressed by the treatment of rosmarinic acid $(\mathrm{p}<0.001$, $55 \%$ staining area of the control) and PSL ( $<<0.001,66 \%$ staining area of the control; fig. 2, 3).

To evaluate the mesangial cell-proliferation, immunohistological staining for PCNA was conducted. As shown in figures 4 and 5, PCNA-positive cell number in a glomerulus of control rats was significantly augmented compared to that of normal rats, which was significantly suppressed by the treatment of rosmarinic acid and PSL ( $p<$ 0.01 , respectively).

In the immunohistological analysis for extracellular matrix proteins, ATS highly induced glomerular depositions of fibronectin, collagen IV and fibrin, which were significantly suppressed by rosmarinic acid $(p<0.001,54$, 57 and 54\% of fibronectin, collagen IV and fibrin-staining areas of the control, respectively), while PSL treatment

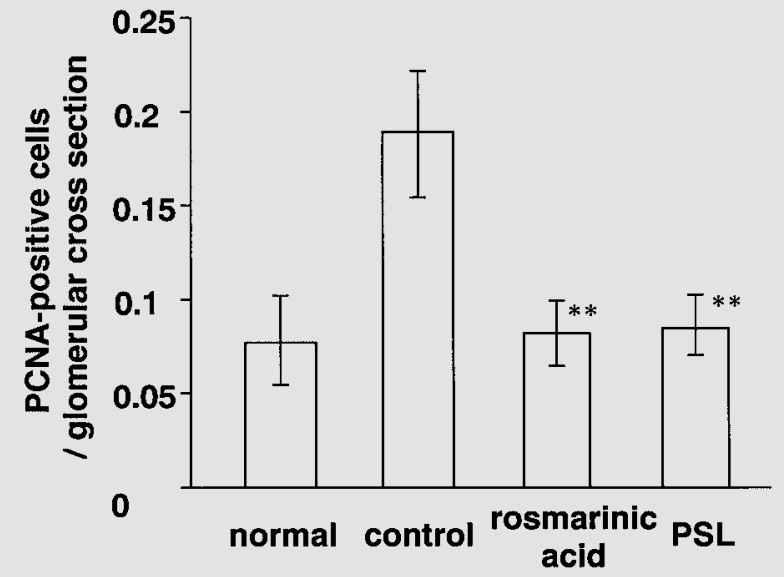

Fig. 5. Suppressive effect of rosmarinic acid on the proliferation of glomerular cells in mesangioproliferative glomerulonephritis induced with ATS. The average number of PCNA-positive cell number of a rat was determined as the mean of positive cell numbers in all glomerular cross-sections. Values are represented as mean $\pm \mathrm{SE}(\mathrm{n}=$ 6). $\mathrm{PSL}=$ Prednisolone. ${ }^{* *} \mathrm{p}<0.01$ vs. control.

did not significantly improve the deposition of these proteins (fig. 6, 7).

SOD activity in the homogenate of renal cortex in the control rats was markedly depleted compared to that in the normal group. This depletion was significantly recovered $(p<0.001)$ by the treatment of rosmarinic acid, while PSL treatment could not improve the depletion (fig. 8). 

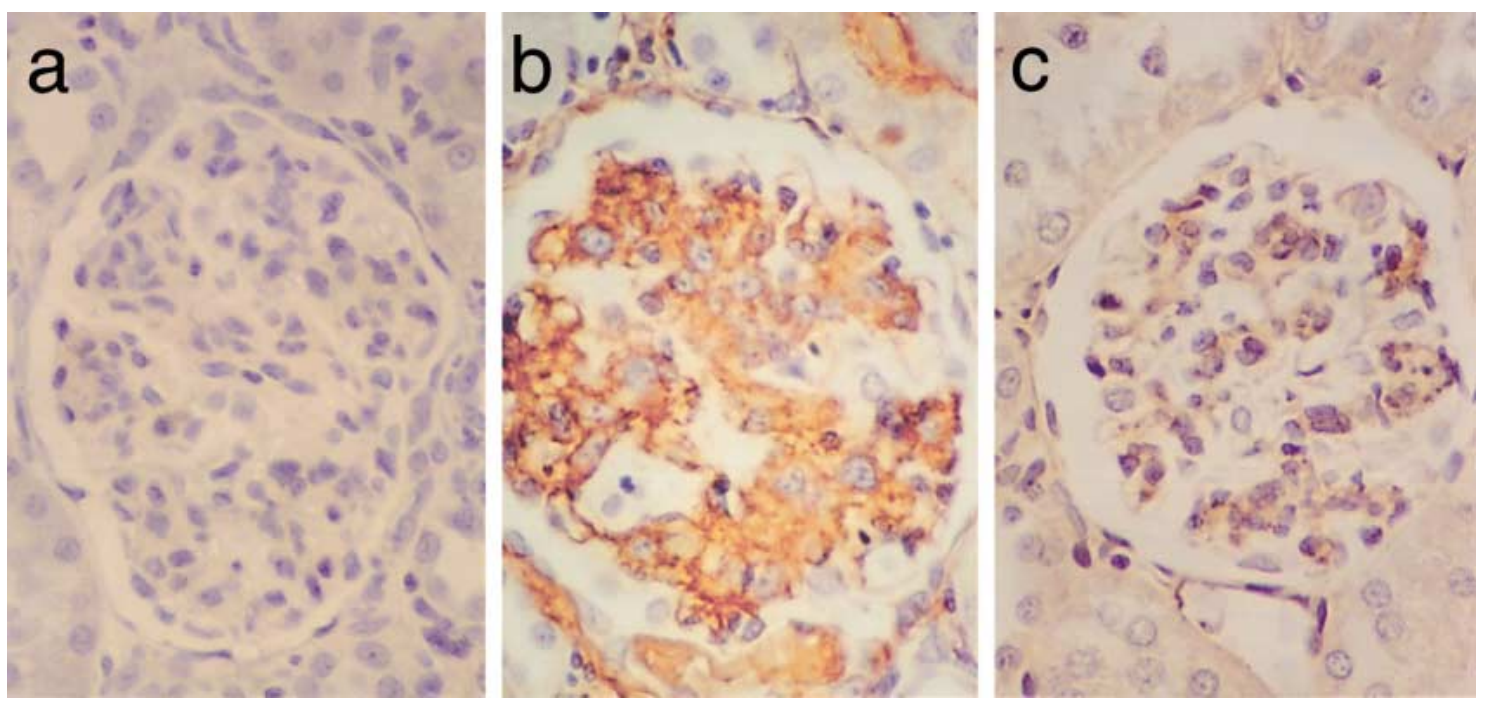

Fig. 6. Fibronectin-stained tissue of mesangioproliferative glomerulonephritis induced with ATS. a Negative staining control; the tissue of disease control rats was stained without primary anti-fibronectin antibody. Fibronectin accumulation was markedly observed in the disease control group (b), which was suppressed by the treatment of rosmarinic acid (c). Final magnifiation, $\times 250$.

\section{Discussion}

Our previous in vitro study revealed that rosmarinic acid, which is widely distributed in Labiatae herbs, inhibited cytokine-induced proliferation of cultured murine mesangial cells [12]. In the present study, we further evaluated the anti-nephritic effect of oral treatment of rosmarinic acid in vivo using rat Thy-1-nephritis, which is an animal model of mesangioproliferative glomerulonephritis frequently used for the screening of antinephritic drugs [18].

In the present study, ATS was intravenously injected to rats at the dose of $0.2 \mathrm{ml} / \mathrm{kg}$, which caused mild mesangioproliferative glomerulonephritis. Indeed, the number of PCNA-positive glomerular cells and the deposition of extracellular matrix proteins in a glomerulus were markedly augmented in control rats compared to normal rats. Oral treatment of rosmarinic acid significantly reduced the number of PCNA-positive glomerular cells in a glomerulus. It is suggested that rosmarinic acid would inhibit the proliferation of mesangial cell, since the proliferating glomerular cells in this model are usually mesangial cells $[13,14]$. It is revealed that rosmarinic acid suppresses the proliferation of mesangial cells not only in murine cultured cells but also in the in vivo rat model.

To examine the involvement of glomerular extracellular matrix accumulation, trichrome staining and immu- nostaining for fibronectin, collagen IV and fibrin were conducted. Compared to the normal group, control rats widely exhibited staining of trichrome and glomerular deposition of fibronectin, collagen IV and fibrin. Previous studies revealed that glomerular deposition of fibrin was detected in rat mesangioproliferative glomerulonephritis induced with antithymocyte monoclonal antibody [21], and that glomerular depositions of fibronectin, laminin, type I collagen and type IV collagen in Thy-1 nephritis were significantly reduced by the injection of tissue plasminogen activator via its antifibrotic activity [22]. These results suggest that fibrin-deposition is clearly related to matrix accumulation in this experimental model. On the other hand, rosmarinic acid inhibited platelet aggregation and promoted fibrinolytic activity without changing the content of plasma fibrinogen in rat thrombotic models [23]. In this study, both rosmarinic acid and PSL suppress the mesangial cell proliferation, while PSL did not suppress glomerular depositions of fibronectin, type IV collagen and fibrin. These results indicated that the suppressive mechanisms of rosmarinic acid differ from those of PSL, and suggested that fibrinolytic activity of rosmarinic acid might be related to its suppressive effect on glomerular matrix accumulation. PSL could not suppress the accumulation of each matrix component but significantly suppress total glomerular matrix expansion exhibited by trichrome staining. It is considered that PSL would sup- 


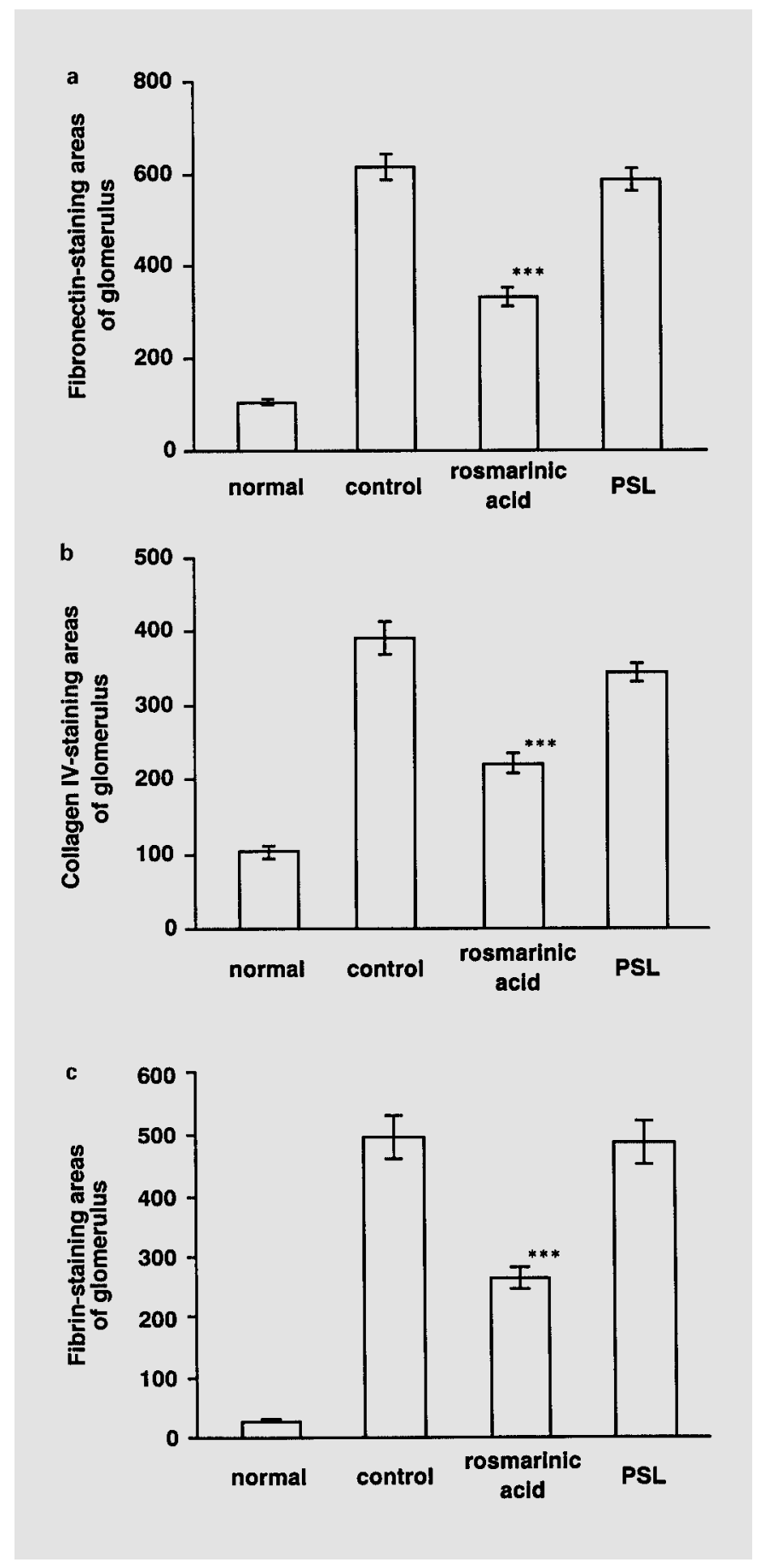

Fig. 7. Effects of rosmarinic acid on accumulation of glomerular matrix proteins. The fibronectin-positive (a), collagen IV-positive (b), and fibrin-positive (c) areas $\left(\mu \mathrm{m}^{2}\right)$ in glomeruli of the rats evaluated by NIH image were shown. Values are represented as mean \pm $\mathrm{SE}(\mathrm{n}=6)$. PSL $=$ Prednisolone. ${ }^{* * *} \mathrm{p}<0.001$ vs. control.

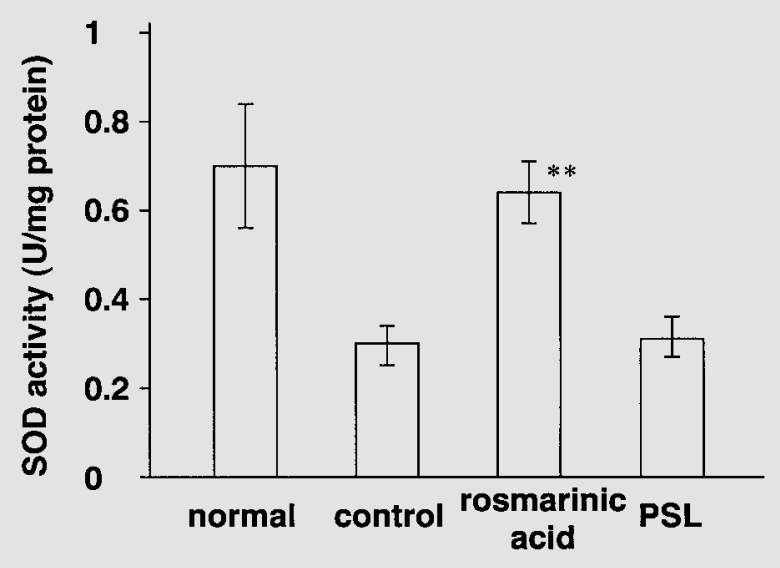

Fig. 8. Effect of rosmarinic acid on SOD activity in the kidney of mesangioproliferative glomerulonephritis induced with ATS. Values are represented as mean \pm SE $(\mathrm{n}=6) . \mathrm{PSL}=$ Prednisolone. ${ }^{* *} \mathrm{p}<$ 0.01 vs. control.

press edematous mesangial expansion due to inflammation.

Reactive oxygen species (ROS) released from inflammatory cells play a critical role in the pathogenesis of Thy1 nephritis [24]. A previous study showed that a scavenger for ROS suppressed urinary protein and the proliferation of mesangial cell in Thy-1 nephritis [25]. Since rosmarinic acid has anti-oxidant activity $[10,11]$, it is strongly suggested that rosmarinic acid would suppress this experimental nephritis by its anti-oxidative action. To evaluate the oxidative status in the glomeruli, SOD activity of renal cortex homogenate was measured. SOD activity in the control rats were depleted compared to that of the normal rats, while this depletion was significantly recovered by the rosmarinic acid treatment. It is suggested that endogenous SOD in the kidney was consumed by ROS released from inflammatory cells, and that rosmarinic acid would scavenge such ROS instead of endogenous SOD. In Masugi's nephritis, which is rat experimental glomerulonephritis induced with anti-glomerular basement membrane serum, ROS released from neutrophils stimulate to produce glomerular fibrin thrombi [26], predicting that the deposition of fibrin in Thy-1 nephritis may also be implicated in ROS. In the present study, rosmarinic acid would suppress glomerular extracellular matrix accumulation, including fibrin, and mesangial cell proliferation via its radical scavenging activity. Since PSL could not recover the depletion of SOD activity in the renal cor- 
tex, anti-proliferative effect of PSL on mesangial cell in vivo would be independent of oxygen radical.

In conclusion, the present study shows that the oral administration of rosmarinic acid results in suppressive effects on rat mesangioproliferative glomerulonephritis through its antifibrotic effect and its scavenging effect of reactive oxygen species. Taken together with our previous in vitro study showing that rosmarinic acid inhibits the proliferation of cultured murine mesangial cells [12], it is suggested that rosmarinic acid is a promising agent for preventing mesangioproliferative glomerulonephritis.

\section{Acknowledgments}

We are grateful to Mr. Hiroto Yoshifusa and Mr. Yutaka Nakamura (Nippon Shin-yaku Co. Ltd.) for kindly providing ATS.

\section{References}

1 Scarpati ML, Oriente G: Isolation and constitution of rosmarinic acid from Rosmarinus officinalis. Ricerca Sci 1958;28:2329-2333.

2 Tada H, Murakami Y, Omoto T, Shimomura $\mathrm{K}$, Ishimaru $\mathrm{K}$ : Rosmarinic acid and related phenolics in hairy root cultures of Ocimum basilicum. Phytochemistry 1996;42:431-434.

3 Agata I, Kusakabe H, Hatano T, Nishibe S, Okuda T: Melitric acid A and B, new trimeric caffeic acid derivatives from Melissa officinalis. Chem Pharm Bull 1993;41:1608-1611.

4 Englberger W, Hadding U, Etshenberg E, Graf E, Leyck S, Winkelmann J, Parnham MJ: Rosmarinic acid: A new inhibitor of complement C3-convertase with anti-inflammatory activity. Int J Immunopharmacol 1988;10:729-737.

5 Peake PW, Pussell BA, Martyn P, Timmermans V, Charlesworth JA: The inhibitory effect of rosmarinic acid on complement involves the C5 convertase. Int J Immunopharmacol 1991; 13:853-857.

6 Sahu A, Rawal N, Pangburn MK: Inhibition of complement by covalent attachment of rosmarinic acid to activated C3b. Biochem Pharmacol 1999;57:1439-1446.

7 Yamamoto H, Sakakibara J, Nagatsu A, Sekiya $\mathrm{K}$ : Inhibitors of arachidonate lipoxygenase from defatted perilla seed. J Agri Food Chem 1998;46:862-865.

8 Ito H, Miyazaki T, Ono M, Sakurai H: Antiallergic activities of rabdosiin and its related compounds: Chemical and biochemical evaluations. Bioorg Med Chem 1998;6:1051-1056.

9 Rimando AM, Inoshiri S, Otsuka H, Kohda H, Yamazaki K, Padolina WG, Torres L, Quintana EG, Cantoria MC: Screening for mast cell histamine release inhibitory activity of Philippine medicinal plants: Active constituent of Ehretia microphylla. Shoyakugaku Zasshi 1987;41:242-247.
10 Tada M, Matsumoto R, Yamaguchi H, Chiba $\mathrm{K}$, Tada M, Matsumoto R, Yamaguchi H: Novel antioxidants isolated from Perilla frutescens Britton var. crispa (Thunb.). Biosci Biotech Biochem 1996;60:1093-1095.

11 Nakamura Y, Ohto Y, Murakami A, Ohigashi $\mathrm{H}$ : Superoxide scavenging activity of rosmarinic acid from Perilla frutescens Britton var. acuta f. viridis. J Agri Food Chem 1998;46: 4545-4550.

12 Makino T, Ono T, Muso E, Yoshida H, Honda $\mathrm{G}$, Sasayama S: Inhibitory effects of rosmarinic acid on the proliferation of cultured murine mesangial cells. Nephrol Dialysis Tramsplant 2000;15:1140-1145.

13 Ishizaki M, Masuda Y, Fukuda Y, Sugisaki Y, Yamanaka N, Masugi Y: Experimental mesangioproliferative glomerulonephritis in rats induced by intravenous administration anti-thymocyte serum. Acta Pathol Jpn 1986;36:11911203.

14 Flöege J, Johnson RJ, Gordon K, Iida H, Pritzl $\mathrm{P}$, Yoshimura A, Campbell C, Alpers CE, Couser WG: Increased synthesis of extracellular matrix in mesangial proliferative nephritis. Kidney Int 1991;40:477-488.

15 Fukui H, Yazaki K, Tabata M: Two phenolic acids from Lithospermum erythrorhizon cell suspension cultures. Phytochemistry 1984;23: 2398-2399.

16 Liu N, Ono T, Suyama K, Nogaki F, Shirakawa K, Maeda M, Kawamura T, Kamata T, Oyama A, Muso E, Sasayama S: Mesangial factor V expression colocalized with fibrin deposition in IgA nephropathy. Kidney Int 2000;58:598606.

17 Higuchi Y, Ono K, Sekita S: Preventive effects of Shichimotsu-koka-to on renal lesions in stroke-prone spontaneously hypertensive rats. Biol Pharm Bull 1998;21:914-918.

18 Hattori T, Shindo S, Hisada T, Fujitsuka N, Hibino T, Terazono Y, Maruno M: Effects of Onpi-to (TJ-8117) on mesangial injury induced by anti Thy-1 antibody. Jpn J Pharmacol 1995; 105:63-75.
19 Iida J, Seifert R, Alpers CE, Gronwald GK, Phillips PE, Pritzl P, Gordon K, Gown AM, Ross R, Bowen-Pope DF, Johnson RJ: PDGF and PDGF-R are induced in mesangial proliferative nephritis in the rat. Proc Natl Acad Sci USA 1991;88:6560-6564.

20 Okuda A, Languino LR, Ruoslahti E, Border WA: Elevated expression of TGF- $\beta$ and proteoglycan production in experimental glomerulonephritis. J Clin Invest 1990;86:453-462.

21 Bagchus WM, Hoedemaeker PJ, Rozing J, Bakker WW: Acute glomerulonephritis after intravenous injection of monoclonal anti-thymocyte antibodies in the rat. Immunol Lett 1986;12:109-113.

22 Haraguchi M, Border WA, Huang Y, Noble NA: t-PA promotes glomerular plasmin generation and matrix degradation in experimental glomerulonephritis. Kidney Int 2001;59:21462155.

23 Zou ZW, Xu LN, Tian JY: Antithrombotic and antiplatelet effects of rosmarinic acid, a watersoluble component isolated from radix Salviae miltiorrhizae (danshen). Acta Pharmac Sin 1993;28:241-245.

24 Nakamura K, Oka M, Shirai M, Igarashi Y, Kojima K, Kaneko O, Hamada N, Mera J, Masaoka H, Nagase M: Source of reactive oxygen species in anti-thy-1 nephritis. Ren Fail 1998;20:399-405.

25 Hamada N, Nagase M: In vivo effect of OPC15161, a superoxide scavenger, on antithy-1 nephritis. Eur J Pharmacol 1996;317: 123-128.

26 Ito S, Sugisaki T, Soezima K: Generation of oxygen radicals and formation of fibrin thrombi in glomerular capillaries of rats with nephrotoxic nephritis. Jpn J Nephrol 1989;31:171177. 